\title{
Bariatric-Metabolic Surgery Utilisation in Patients With and Without Diabetes: Data from the IFSO Global Registry 2015-2018
}

\author{
Richard Welbourn ${ }^{1}$ (D) Marianne Hollyman ${ }^{1}$ (D) $\cdot$ Robin Kinsman ${ }^{2} \cdot$ John Dixon $^{3} \cdot$ Ricardo Cohen $^{4} \cdot$ John Morton $^{5}$. \\ Amir Ghaferi ${ }^{6}$. Kelvin Higa ${ }^{7}$. Johan Ottosson ${ }^{8} \cdot$ Francois Pattou $^{9}$. Salman Al-Sabah ${ }^{10}$. Merhan Anvari ${ }^{11}$. \\ Jacques Himpens ${ }^{12} \cdot$ Ronald Liem ${ }^{13} \cdot$ Villy Våge $^{14} \cdot$ Peter Walton $^{2} \cdot$ Wendy Brown ${ }^{15} \cdot$ Lilian Kow $^{16}$
}

Received: 22 October 2020 / Revised: 3 February 2021 / Accepted: 9 February 2021 / Published online: 27 February 2021

(C) The Author(s) 2021

\begin{abstract}
Background Comparative international practice of patients undergoing bariatric-metabolic surgery for type 2 diabetes mellitus (T2DM) is unknown. We aimed to ascertain baseline age, sex, body mass index (BMI) and types of operations performed for patients with T2DM submitted to the IFSO Global Registry.

Materials and Methods Cross-sectional analysis of patients having primary surgery in 2015-2018 for countries with $\geq 90 \%$ T2DM data completion and $\geq 1000$ submitted records.

Results Fifteen countries including 11 national registries met the inclusion criteria. The rate of T2DM was $24.2 \%$ (99,537 of 411,581 patients, country range $12.0-55.1 \%$ ) and $77.1 \%$ of all patients were women. In every country, patients with T2DM were older than those without T2DM (overall mean age 49.2 [SD 11.4] years vs 41.8 [11.9] years, all $p<0.001$ ). Men were more likely to have T2DM than women, odds ratio (OR) 1.68 (95\% CI 1.65-1.71), $p<0.001$. Men showed higher rates of T2DM for BMI $<35 \mathrm{~kg} / \mathrm{m}^{2}$ compared to BMI $\geq 35.0 \mathrm{~kg} / \mathrm{m}^{2}$, OR $2.76(2.52-3.03), p<0.001$. This was not seen in women, OR $0.78(0.73-0.83), p$ $<0.001$. Sleeve gastrectomy was the commonest operation overall, but less frequent for patients with T2DM, patients with T2DM 54.9\% vs without T2DM 65.8\%, OR $0.63(0.63-0.64), p<0.001$. Twelve out of 15 countries had higher proportions of gastric bypass compared to non-bypass operations for T2DM, OR $1.70(1.67-1.72), p<0.001$.

Conclusion Patients with T2DM had different characteristics to those without T2DM. Older men were more likely to have T2DM, with higher rates of BMI $<35 \mathrm{~kg} / \mathrm{m}^{2}$ and increased likelihood of food rerouting operations.
\end{abstract}

Keywords Obesity surgery $\cdot$ Bariatric surgery $\cdot$ Demographic classification $\cdot$ Comorbidity $\cdot$ Sex characteristics $\cdot$ Type 2 diabetes $\cdot$ IFSO Global Registry $\cdot$ Operation choice for diabetes $\cdot$ Metabolic surgery

Richard Welbourn

Richard.Welbourn@Somersetft.nhs.uk

1 Department Upper GI and Bariatric Surgery, Musgrove Park Hospital, Taunton TA1 5DA, UK

2 Dendrite Clinical Systems Ltd., Henley-on-Thames, Oxfordshire RG9 1AY, UK

3 Iverson Health Innovation Research Institute, Swinburne University, Melbourne, Australia

4 The Center for Obesity and Diabetes, Oswaldo Cruz German Hospital, São Paulo, Brazil

5 Division Chief, Bariatric and Minimally Invasive Surgery, Yale School of Medicine, New Haven, CT, USA

6 Department of Surgery, University of Michigan, Ann Arbor, MI, USA

7 UCSF, Fresno, CA, USA
8 Department of Surgery, Faculty of Medicine and Health, Örebro University, Orebro, Sweden

9 Faculty of Medicine, University of Lille, Lille, France

10 Al-Amiri Hospital Kuwait, Royale Hyatt Hospital, Kuwait City, Kuwait

11 Department of Surgery, McMaster University, Hamilton, Ontario, Canada

12 CHIREC Delta Hospital, Brussels, Belgium

13 Department of Surgery, Groene Hart Hospital, Gouda, Netherlands

14 Scandinavian Obesity Surgery Registry, Bergen, Norway

15 Centre of Obesity Research and Education, Monash University, Melbourne, Australia

16 College of Medicine and Public Health, Flinders University, Adelaide, Australia 


\section{Introduction}

Over the last decade, randomised controlled trials (RCTs) [1-5], systematic reviews, meta-analyses $[6,7]$ and international guidelines [8-11] have indicated the benefits of bariatric-metabolic surgery for patients with type 2 diabetes mellitus (T2DM) and severe obesity compared to medical therapy alone. 'Bariatric' surgery that produces weight loss overlaps with 'metabolic' or 'diabetes' surgery where the aim is to improve conditions such as T2DM [12]. The term metabolic surgery has been defined as 'the operative manipulation of a normal organ or organ system to achieve a biological result for a potential health gain', and has come to embrace any intervention of the gastrointestinal tract that improves T2DM, regardless of baseline body mass index (BMI) [13], while bariatric surgery, from the Greek 'baros' weight or pressure, and '-iatric', the medicine or surgery thereof, has weight loss and its associated benefit as the primary endpoint. 'Bariatric-metabolic surgery' is now commonly used to denote the entirety of this area of surgery.

Bariatric-metabolic surgery also improves a range of other obesity-related diseases, provides survival benefit and is cost effective $[14,15]$. Despite many international bariatric surgical societies also adding the word 'metabolic' to their names to emphasise these positive effects of the procedures, the penetrance of bariatric-metabolic surgery continues to be very low compared to the large number of people who might benefit [16].

There are few comparative data on which patients worldwide are receiving bariatric-metabolic surgery [17, 18]. Mapping current international practices could provide a baseline for strategies to increase its availability and uptake. The International Federation of Surgery for Obesity (IFSO) has undertaken several surveys, mostly relying on estimates, over the last 20 years [19-23]. These reports were able to describe only operation type and procedure numbers, without details on demography or obesity-related disease. A description of which patients with T2DM are receiving this surgery on an international basis and whether having T2DM influences the procedure undertaken is currently lacking.

In 2014, IFSO established a Global Registry project partly to fill these knowledge gaps [24]. The $5^{\text {th }}, 2019$ report, contained descriptive information for 833,687 anonymised individual patient records from 61 countries including 17 national registries, 25 multi-centre submissions and 19 single centres accumulated since its inception [25]. So far 2 reports have described broad characteristics for the submitted data $[17,18]$. The Global Registry can potentially provide a detailed description of uptake of bariatric-metabolic surgery for T2DM. We hypothesised that countries with higher prevalence of disease would have a greater proportion of operated patients with T2DM.
This study aimed to describe the differences in demographic data and type of bariatric and metabolic surgery performed in patients with and without T2DM according to the IFSO Global Registry 2015-2018. A secondary aim was to estimate the relative rates of surgery performed for patients with T2DM by comparison to T2DM prevalence in each country's general adult population.

\section{Materials and Methods}

\section{Study Design and Participants}

A cross-sectional study was performed of the baseline data for patients with or without T2DM having primary bariatricmetabolic surgery from the IFSO Global Registry 2019 data cut. STROBE guidelines were followed. A certificate of exemption from NHS Research Ethics Committee (REC) approval for the study was obtained from the UK Human Research Authority decision tools available on the website http://www.hra-decisiontools.org.uk/ethics/. Countries were chosen that had $\geq 90 \%$ complete baseline T2DM data and $\geq$ 1000 individual anonymised patient records for the calendar years 2015-2018. As this was an observational study it was not powered to detect a specified difference between analysed groups.

Data were uploaded either individually by each submitting centre or by an upload from the national registry as previously described $[17,18]$. The contributors were reassured that no statistical comparison would be attempted between different countries for outcomes that would differentiate quality such as complications or mortality.

Data for individual country prevalence of T2DM were accessed from the Non-Communicable Diseases Risk Factor Collaboration (NCD-RisC) for adults aged 18 years or over using 2014, the latest available year data [26]. These provided a basis for estimating whether the proportion of patients who had T2DM at the time of operation varied according to country disease prevalence. Data for T2DM prevalence for the same age and BMI range as those patients presenting for bariatric-metabolic surgery in each country were not available.

\section{Procedures}

The procedures in the data set (version 4.1) were as described previously and comprised gastric band/gastric bypass/sleeve gastrectomy/duodenal switch/duodenal switch with sleeve/ biliopancreatic diversion with sleeve/biliopancreatic diversion/other, and type of gastric bypass: Roux-en-Y (RYGB) or one anastomosis (OAGB) [17, 18]. 


\section{Outcomes}

Other variables collected were age or date of birth, sex, height, weight, T2DM defined as being on medication yes/no. Only valid records, defined as those including height, weight and calculated BMI, were included for analysis. Data were grouped according to T2DM on medication, age, sex and BMI. The BMI groups were stratified according to obesity severity $<35.0$ (class I), 35.0-39.9 (class II), 40.0-49.9 (class III), and $>49.9 \mathrm{~kg} / \mathrm{m}^{2}$. Types of operation were assessed to investigate practice undertaken for T2DM according to BMI groupings.

\section{Statistical Analysis}

After skewness and kurtosis testing, continuous data were described by means (standard deviation), means (95\% confidence intervals) and compared by independent sample $t$ test. Categorical data were compared by $\chi^{2}$ with Bonferroni correction for multiple comparisons and odds ratios (ORs) with $95 \%$ CIs. Where multiple comparisons were made, $p<0.003$ was taken to indicate statistical significance. A sensitivity analysis was performed to adjust for the potential dominant effect of the USA on outcomes as $72 \%$ of all data were from this country.

\section{Results}

Forty-six of 61 countries that contributed data to the Global Registry 2015-2018 had completion rates of $\geq 90 \%$ for baseline T2DM status, and 26 countries submitted $\geq 1000$ records. Fifteen countries met the inclusion criteria and had data available for further analysis, including 11 of the 14 contributing national registries, comprising $69.5 \%(413,048)$ of the 594,235 operation records for the date range (2015-2018) of the 5th IFSO report. The mean baseline T2DM data completion rate was $99.6 \%$ (country range $93.7-100 \%$ ). The number on medication for T2DM was 99,537 of 411,581 (24.2\%, country range $12.0-55.1 \%$ ) and $77.1 \%$ of the overall population was female. The total numbers of operations, numbers per country with T2DM, rates of female patients and BMI are shown (Tables 1 and 2). No sex data were available for Chile. OAGB was not separately identified in the USA during the study period.

\section{Demographic Characteristics of Those with and Without T2DM}

In every country, patients with T2DM were older than those without T2DM (overall mean age 49.2 (11.4) years vs 41.8 (11.9) years, all $p<0.001$ ) (Table 2). Men were older than women irrespective of T2DM status. The mean ages of men and women with T2DM were 50.9 (11.1) years and 48.5 (11.5) years respectively, $p<0.001$, and for those without T2DM 42.3 (12.1) years and 41.8 (11.8) years respectively, $p<0.001$.

The overall BMI was slightly higher for those with T2DM (mean $46.9(8.7) \mathrm{kg} / \mathrm{m}^{2}$ vs $46.2(8.1) \mathrm{kg} / \mathrm{m}^{2}, p<0.001$ ). However, the BMI was higher in only 4 countries including the USA, the biggest contributor to the dataset, lower in 4 countries, and similar in 7 countries (Table 2). The majority of all patients with T2DM were in the BMI range 40.0-49.9 $\mathrm{kg} / \mathrm{m}^{2}$, despite the older age of those with T2DM.

The proportions of operated patients with T2DM varied widely from country to country. Sweden $(12.0 \%)$ and France (12.3\%) had the lowest, and Austria (55.1\%) had the highest proportion of patients with T2DM (Fig. 1, Supplementary file Table 1).

The proportions of patients with T2DM in each obesity class are shown (Fig. 1, Supplementary file Table 1). A larger proportion of men were represented in the lower BMI classes, OR for BMI $<35 \mathrm{~kg} / \mathrm{m}^{2}$ compared to $\geq 35.0 \mathrm{~kg} / \mathrm{m}^{2} 2.76(2.52$ 3.03), $p<0.001$ (Supplementary file Tables 2,3 ). For women the equivalent $\mathrm{OR}$ was less than 1 with higher rates of T2DM in higher BMI ranges, OR 0.78 (0.73-0.83), $p<0.001$. The USA contributed $72 \%$ of the patients, and when the remaining $28 \%$ of patients were analysed separately, the trends still remained for men, OR 2.47 (2.22-2.75), and for women, OR $0.85(0.78-0.92)$, both $p<0.001$.)

In 9 of 14 countries there were proportionately more men with T2DM compared to women with T2DM $(p<0.001)$. In Bahrain, Egypt, Kuwait Qatar, and UAE proportions were similar (Table 1). Overall, men had $68 \%$ greater odds for having T2DM compared to women (32\%/21.9\%, OR 1.68 (1.65-1.71), $p<0.001$, Supplementary file Tables 2, 3). This pattern was not altered by excluding the USA data, OR $1.91(1.85-1.97), p<0.001)$.

\section{Proportions of Operated Patients with T2DM Compared to Country T2DM Prevalence}

The proportion of operated male and female patients with T2DM for each country is shown compared to the individual country prevalence of T2DM (adults age $\geq 18$ years) (Fig. 2, Supplementary file Table 4). Countries have been ordered by an increased prevalence of T2DM and a prevalence line indicated in Fig. 2. For Austria the proportion of patients with T2DM choosing surgery was well above the national prevalence rate for both sexes: $60.5 \%$ (56.6$64.4 \%$ ) men had T2DM, 53.6\% (51.1-56.1\%) women had T2DM. In contrast for 2 countries, the proportions choosing surgery were below the prevalence rates for men, and for 3 countries, they were below the prevalence rates for women. 


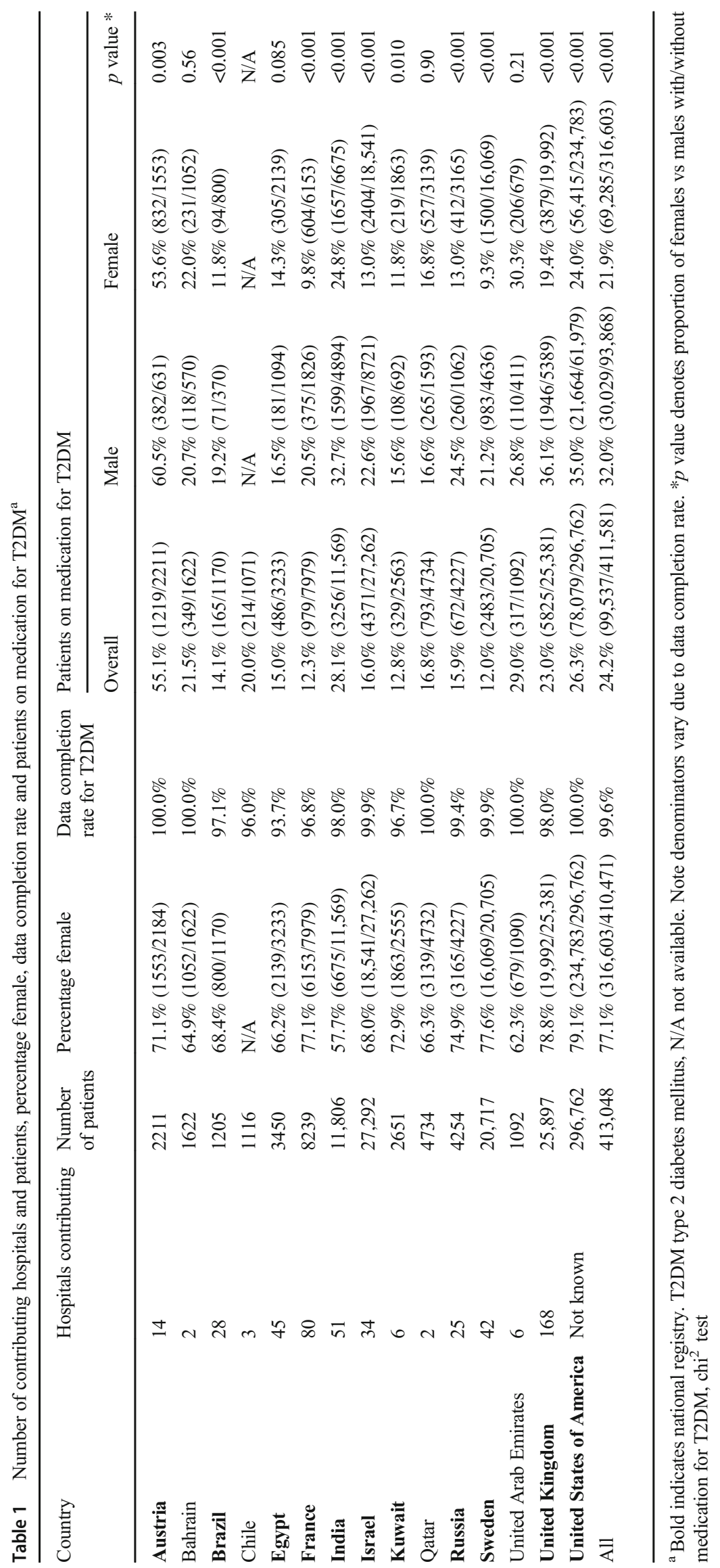


Table 2 Mean age and BMI for patients with or without medication for T2DM ${ }^{\mathrm{a}}$

\begin{tabular}{|c|c|c|c|c|c|c|}
\hline \multirow[b]{2}{*}{ Country } & \multicolumn{3}{|c|}{ Age (mean (SD), y) } & \multicolumn{3}{|c|}{ Initial BMI (mean (SD), $\mathrm{kg} / \mathrm{m}^{2}$ ) } \\
\hline & $\begin{array}{l}\text { Patients not on } \\
\text { medication for } \\
\text { T2DM }\end{array}$ & $\begin{array}{l}\text { Patients on } \\
\text { medication } \\
\text { for T2DM }\end{array}$ & $p$ value & $\begin{array}{l}\text { Patients not on } \\
\text { medication } \\
\text { for T2DM }\end{array}$ & $\begin{array}{l}\text { Patients on } \\
\text { medication } \\
\text { for T2DM }\end{array}$ & $p$ value \\
\hline Austria & $37.1(12.1)$ & $40.8(12.5)$ & $<0.001$ & $44.6(7.1)$ & $45.1(6.9)$ & 0.15 \\
\hline Bahrain & $33.0(9.7)$ & $42.3(11.0)$ & $<0.001$ & $46.2(7.8)$ & $45.0(9.9)$ & 0.017 \\
\hline Brazil & $36.8(10.0)$ & $45.5(11.2)$ & $<0.001$ & $41.5(6.8)$ & $40.8(6.4)$ & 0.22 \\
\hline Chile & $38.5(9.4)$ & $46.5(8.7)$ & $<0.001$ & $37.2(3.9)$ & $36.5(4.1)$ & 0.029 \\
\hline Egypt & $34.6(10.4)$ & $44.2(9.5)$ & $<0.001$ & $46.0(8.2)$ & $48.4(9.2)$ & $<0.001$ \\
\hline France & $40.3(11.8)$ & $50.8(10.5)$ & $<0.001$ & $41.9(6.0)$ & $42.9(6.4)$ & $<0.001$ \\
\hline India & $39.6(12.3)$ & $48.9(10.7)$ & $<0.001$ & $44.0(7.8)$ & $43.0(8.0)$ & $<0.001$ \\
\hline Israel & $38.5(12.1)$ & $50.7(10.9)$ & $<0.001$ & $42.2(4.8)$ & $41.3(5.8)$ & $<0.001$ \\
\hline Kuwait & $31.3(10.4)$ & $42.8(11.3)$ & $<0.001$ & $44.0(7.5)$ & $44.3(8.4)$ & 0.44 \\
\hline Qatar & $31.5(10.9)$ & $34.6(12.1)$ & $<0.001$ & $42.9(6.0)$ & $42.1(6.0)$ & 0.001 \\
\hline Russia & $39.9(10.4)$ & $49.3(9.5)$ & $<0.001$ & $45.3(9.3)$ & $46.9(9.6)$ & $<0.001$ \\
\hline Sweden & $39.8(11.2)$ & $48.2(10.4)$ & $<0.001$ & $41.0(5.8)$ & $41.2(5.8)$ & 0.089 \\
\hline United Arab Emirates & $33.2(9.8)$ & $39.5(10.5)$ & $<0.001$ & $43.9(5.9)$ & $42.3(6.6)$ & 0.000 \\
\hline United Kingdom & $43.5(11.3)$ & $50.4(10.0)$ & $<0.001$ & $46.8(8.0)$ & $46.6(7.8)$ & 0.13 \\
\hline United States of America & $42.9(11.7)$ & $49.5(11.4)$ & $<0.001$ & $47.4(8.3)$ & $47.8(8.8)$ & $<0.001$ \\
\hline All & $41.8(11.9)$ & $49.2(11.4)$ & $<0.001$ & $46.2(8.1)$ & $46.9(8.7)$ & $<0.001$ \\
\hline
\end{tabular}

${ }^{\text {a }}$ Bold indicates national registry. T2DM type 2 diabetes mellitus. $p$ value independent sample $t$ test

\section{Procedure Performed Based on T2DM Status}

Together, RYGB, OAGB and SG comprised $94.4 \%$ of total procedures for those without T2DM and $95.3 \%$ for those with T2DM (Supplementary file Table 5). For those without T2DM the individual operations comprised RYGB $25.1 \%$, OAGB $3.4 \%$ and SG $65.8 \%$. For those with T2DM the individual operations comprised RYGB 36.4\%, OAGB $4.0 \%$ and SG 54.9\%, OR 0.63 (0.63-0.64), $p<0.001$ for SG vs non-SG for patients with T2DM. Twelve of 15 countries had higher proportions of gastric bypass (RYGB or OAGB) compared to SG operations for patients with T2DM compared to those without T2DM (Fig. 3/Supplementary file Table 5), OR 1.70 (1.67-1.72), $p<0.001$. The equivalent OR with USA data excluded was $1.94(1.88-2.00), p<0.001$. There were no significant differences for Austria, Kuwait or Qatar.

\section{Discussion}

We describe the age, sex, BMI, relative proportions of operations per obesity class, and the operations undertaken for patients with T2DM compared to those without T2DM having primary bariatric-metabolic surgery in 15 countries in the IFSO Global Registry. Fewer men underwent surgery than women, and patients with T2DM were 7.4 years older than those without T2DM. Overall, regardless of the presence of
T2DM, men were older than women and were proportionately more likely to have T2DM. In the majority of countries, particularly the 5 Middle Eastern countries, SG was the main operation for all patients irrespective of T2DM status, consistent with other reports [23]. However, T2DM was associated with a higher likelihood of diversionary surgery, either RYGB or OAGB, in nearly every country.

It has been shown previously that offering surgery to treat metabolic disease or diabetes rather than as a mere weightreduction therapy changes demographic and clinical characteristics of surgical candidates [11]. Thus, men in our study appear more likely to seek surgery once they have developed T2DM. The presentation of patients with T2DM at an older age for surgery is in keeping with the increasing population prevalence for the disease with increasing age $[27,28]$. Only $22.9 \%$ of the patients overall were men. On a population basis, the NCDRisC data for BMI groups indicate that about one third of those with a BMI $>35 \mathrm{~kg} / \mathrm{m}^{2}$ are men in the countries studied [26]. This may provide some explanation for the relatively few men having bariatric-metabolic surgery. Many other large population-based studies have reported relative lack of uptake by men for bariatric-metabolic surgery [29-31]. A similar sex pattern emerges for recruiting participants into RCTs for T2DM comparing weight loss drugs. Sixty-four percent of those recruited for a liraglutide RCT as a therapy for T2DM were men [32], in contrast only $32 \%$ of those recruited for a liraglutide weight loss RCT were men [33]. 
Primary surgery: Patients on medication for type 2 diabetes prior to surgery, initial BMI and gender; calendar years 2015-2018

$\begin{array}{llll}\text { - } \mathrm{BMI}<35.0 & \mathrm{BMI} 35.0-39.9 & \mathrm{BMI} 40.0-49.9 & \mathrm{BMI}>49.9\end{array}$

Male patients Female patients
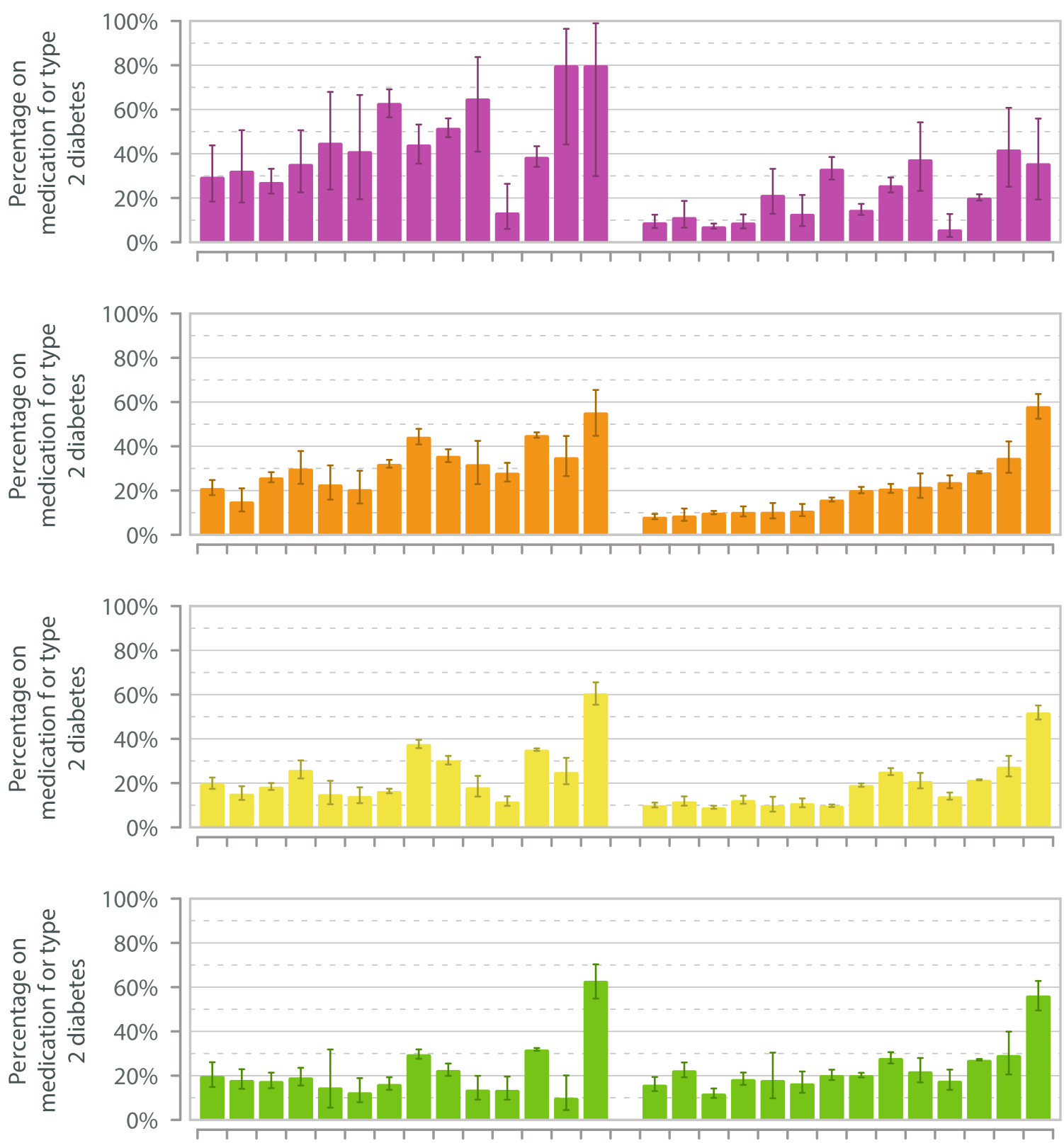

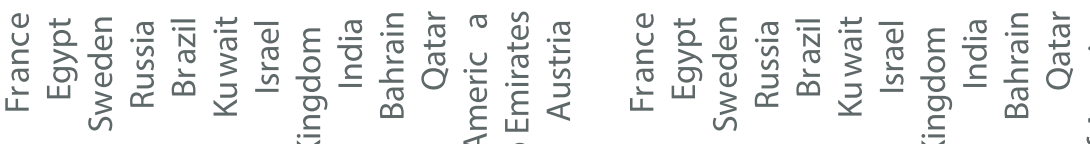
들 
Fig. 1 Primary surgery: male and female patients on medication for T2DM prior to surgery and initial BMI; calendar years 2015-2018. Data are rates (error bars $95 \% \mathrm{CI}$ ) ordered by increasing rate of T2DM per country for BMI range $35.0-39.9 \mathrm{~kg} / \mathrm{m}^{2}$ in women. T2DM, type 2 diabetes mellitus; BMI, body mass index

The reasons for the differences in BMI for patients with or without T2DM in different countries are not known. Several international guidelines have lowered the BMI-based eligibility threshold down to $30 \mathrm{~kg} / \mathrm{m}^{2}$ specifically for T2DM, and lower for Asians [9-11]. Especially for male patients, there was evidence that metabolic surgery for T2DM was being taken up in every country for class 1 obesity (Fig. 1). However, the smaller proportion of women with T2DM compared to men with T2DM suggests sex-specific motivational factors for choosing bariatric-metabolic surgery for class 1 obesity.

A previous study has shown extremely low uptake worldwide for bariatric-metabolic surgery for patients with obesity and T2DM [34]. For both sexes, in most countries the proportions receiving surgery were above the national prevalence line for T2DM prevalence, as shown in Fig. 2. However, the NCD-RisC T2DM prevalence data were for the general population, and not specifically for those with BMI > $35 \mathrm{~kg} / \mathrm{m}^{2}$ and an average age of over 49 years, for which the prevalence would be much higher. Country-specific data for T2DM in the BMI-eligible population are lacking. However, the observation that the rates of surgery were below the national prevalence line for both sexes in some countries suggests a bias for those without diabetes to be offered and/or choose bariatricmetabolic surgery. Meanwhile, the countries with a level well above the line, for instance Austria, suggest a national trend to offer surgery for T2DM.

SG and RYGB are established procedures for T2DM, and IFSO supports OAGB as an effective procedure for this disease [35]. Although SG was the dominant operation for all patients, the higher usage of RYGB or OAGB for those with T2DM in 12 of 15 countries was significant. Removing from analysis the country contributing the majority of patients (USA) made the effect even more marked. The higher prevalence of bypass operations is in agreement with the literature. Among the 4 RCTs that compared SG and RYGB, only one had T2DM remission as an endpoint and was favourable to RYGB [2-5].

An overarching goal of the IFSO Global Registry is to achieve complete descriptive coverage of international bariatric practice, similar to existing reports of global obesity prevalence [36]. Therefore, future reports may be able to describe changing trends over time in the patients receiving bariatricmetabolic surgery, or differences in the operation done according to the severity or duration of disease in the whole operated population. Standardised international datasets recording anti-diabetes treatments would enable this. Other priorities for external validity of the international registry include verification of accuracy in submitted records and complete case ascertainment.

A strength of the study is the large number of patients and countries analysed, with individual-level actual data not based

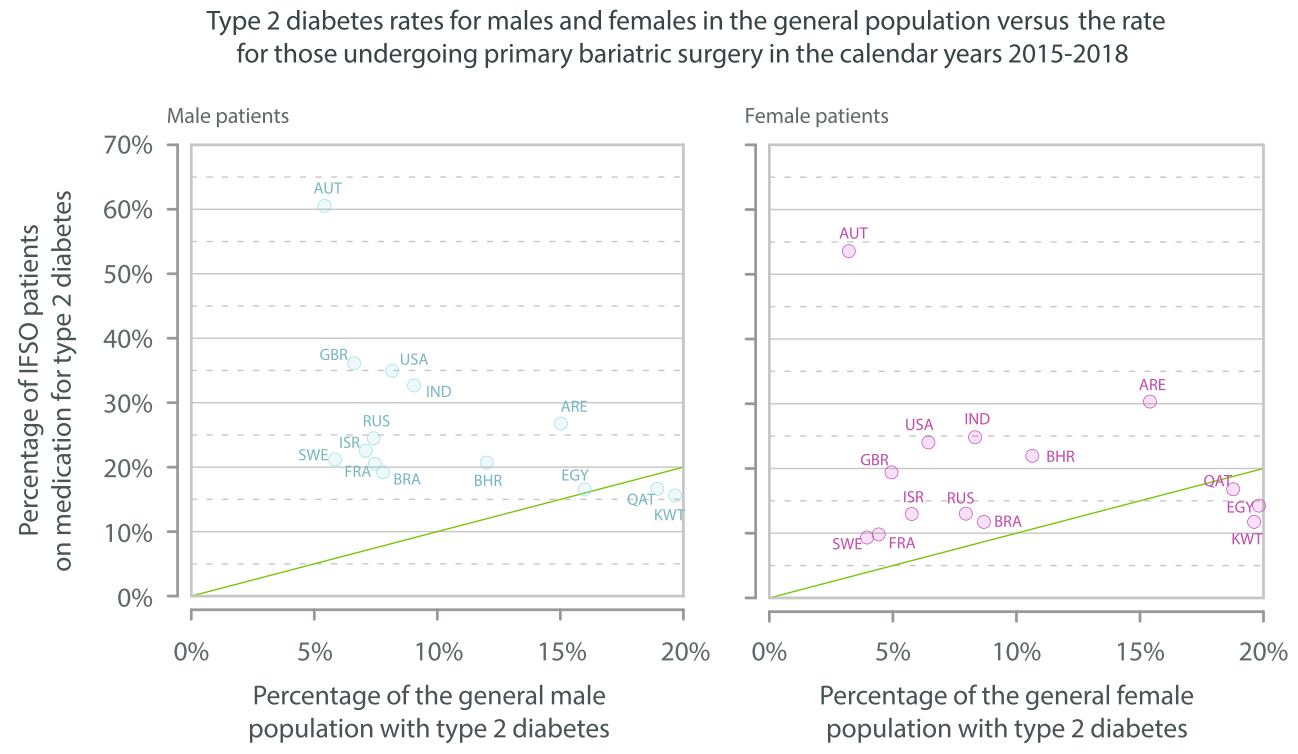

Fig. 2 T2DM rates for adult men and women in the general adult (age $\geq$ 18 years) population from NCD-RisC, calendar year 2014, versus the rate for patients on medication for T2DM undergoing primary bariatric surgery, calendar years 2015-2018. Oblique line represents parity for general adult population prevalence of T2DM and proportion of operated patients on medication for T2DM. T2DM, type 2 diabetes

mellitus; NCD-RisC, Non-Communicable Diseases Risk Factor Collaboration; AUT, Austria; BHR, Bahrain; BRA, Brazil; EGY, Egypt; FRA, France; IND, India; ISR, Israel; KWT, Kuwait; QAT, Qatar; RUS, Russia; SWE, Sweden; ARE, United Arab Emirates; GBR, United Kingdom; USA, United States of America 
Primary surgery: Kind of operation performed according to treatment for type 2 diabetes pre-operatively; calendar years 2015-2018
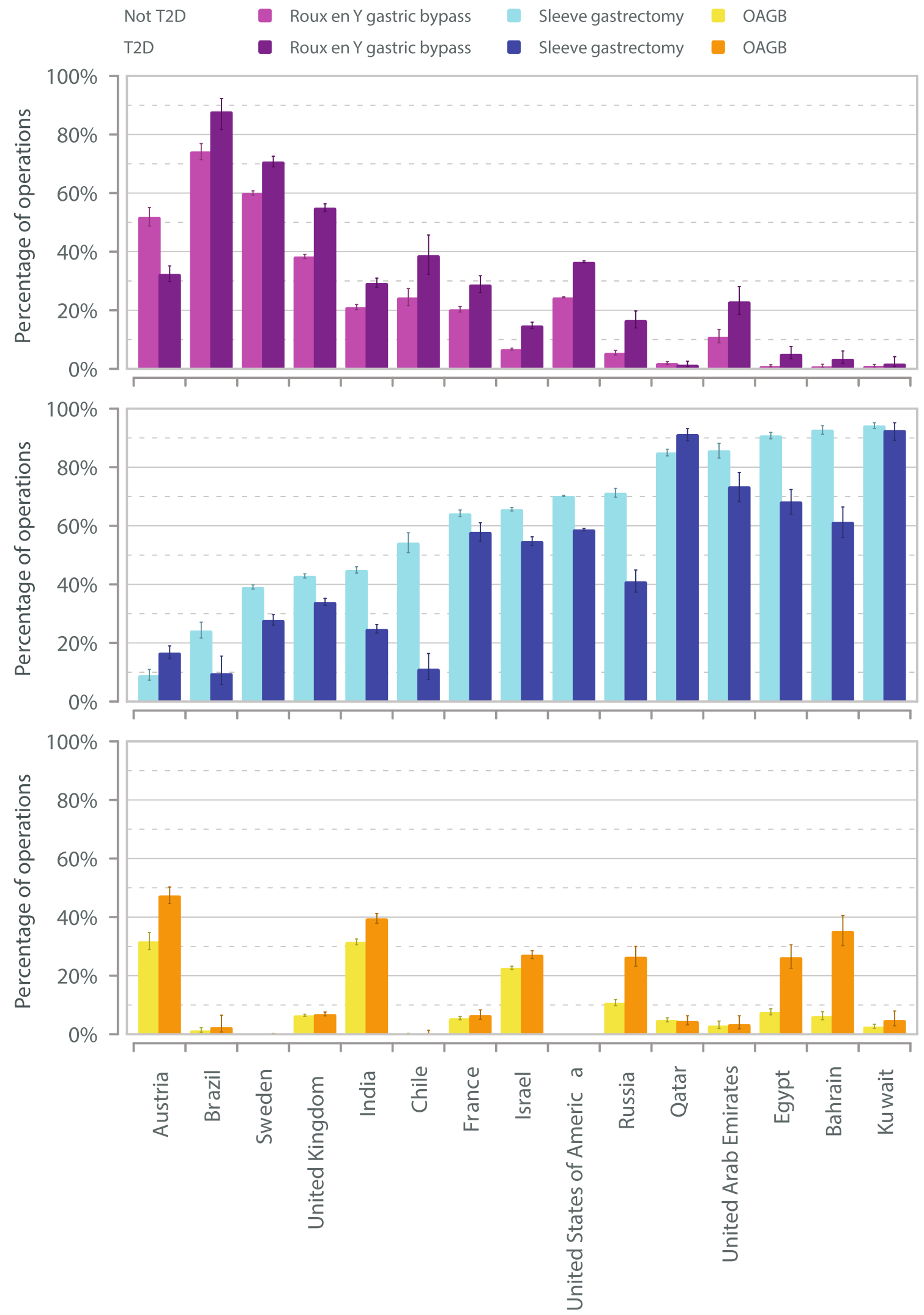

Country 
Fig. 3 Primary surgery: type of operation performed for patients with or without medication for T2DM pre-operatively; calendar years 20152018 , ordered by increasing rate of SG for patients without medication for T2DM. Data are rates (error bars 95\% CI). T2DM, type 2 diabetes mellitus; SG, sleeve gastrectomy

on estimates or surveys. Another strength is the more than 99\% data completion rate for baseline T2DM albeit based on taking medications for diabetes.

Our study has several limitations. We are unable to assess whether the data are representative of individual country practice, except for Sweden, USA and Israel that have known near complete case ascertainment [30, 31, 37, 38]. For the other national registries data submission was not compulsory and it is unknown what proportion of practices submitted data. We are unable to exclude unknown observer or selection bias. Another limitation is that the reason(s) for patients choosing to have bariatricmetabolic surgery were not included in the dataset. Therefore it is not known whether patients with T2DM chose to have surgery for weight loss or to improve metabolic status. We also do not know whether operation choices were influenced by severity of T2DM. Due to the lack of individual country data on the prevalence of T2DM in individuals with BMI $>35 \mathrm{~kg} / \mathrm{m}^{2}$, we were also unable to assess prioritisation of patients for metabolic surgery more accurately. Stratification by public health service or insurance/private funding was beyond the scope of the present study. As our data were cross-sectional we were unable to estimate changes over time. Another limitation is that the duration of T2DM was not recorded in the dataset.

\section{Conclusions}

We found major differences in age, sex and uptake in patients with T2DM having bariatric-metabolic surgery compared to the operated population without T2DM, associated with a significant increased likelihood of a form of gastric bypass for patients with T2DM. Surgery for T2DM, or metabolic surgery, changes the landscape of the patient demographics. Overall, SG still predominated. The data could provide a knowledge base for healthcare systems considering frameworks for treating patients with T2DM.

Supplementary Information The online version contains supplementary material available at https://doi.org/10.1007/s11695-021-05280-6.

Funding The IFSO contracted Dendrite Clinical Systems Ltd to be the data processor for the Global Registry and invited member countries to submit data. The Global Registry committee invited, but did not fund, the corresponding author to design the study, analyze and interpret data, write the report, and submit the paper for publication. The corresponding author had final responsibility for the decision to submit for publication.

\section{Declarations}

This article does not contain any studies with human participants or animals performed by any of the authors. For this type of study, formal consent was not required. A certificate of exemption from NHS Research Ethics Committee (REC) approval for the study was obtained from the UK Human Research Authority decision tools available on the website http://www.hra-decisiontools.org.uk/ethics/.

Conflict of Interest Dr Welbourn reports personal fees from Novo Nordisk, outside the submitted work.

Drs Kinsman and Walton report grants from IFSO, outside the submitted work.

Dr Dixon reports personal fees from NHMRC, during the conduct of the study; personal fees from Reshape, personal fees from Bariatric Advantage, personal fees from Novo Nordisk, personal fees from Nestle Health Science, personal fees from Johnson \& Johnson, and personal feed from I-Nova, outside the submitted work.

Dr Cohen reports personal fees from GI Dynamics, grants from Johnson \& Johnson Medical, Brazil, outside the submitted work.

Dr Ottosson reports consultancy fees from Johnson \& Johnson and Vifor Pharma, outside the submitted work.

Dr Anvari reports consultancy fees from Johnson \& Johnson, outside the submitted work.

Dr Himpens reports personal fees from Ethicon, personal fees from Medtronic, outside the submitted work.

Dr Brown reports grants from Johnson and Johnson, grants from Medtronic, grants from GORE, personal fees from GORE, grants from Applied Medical, grants from Apollo Endosurgery, grants and personal fees from Novo Nordisk, personal fees from Merck Sharpe and Dohme, outside the submitted work; and I am a bariatric surgeon so earn my living from performing these procedures.

Drs Hollyman, Morton, Ghaferi, Higa, Pattou, Al-Sabah, Liem, Våge, Kow have nothing to disclose.

Open Access This article is licensed under a Creative Commons Attribution 4.0 International License, which permits use, sharing, adaptation, distribution and reproduction in any medium or format, as long as you give appropriate credit to the original author(s) and the source, provide a link to the Creative Commons licence, and indicate if changes were made. The images or other third party material in this article are included in the article's Creative Commons licence, unless indicated otherwise in a credit line to the material. If material is not included in the article's Creative Commons licence and your intended use is not permitted by statutory regulation or exceeds the permitted use, you will need to obtain permission directly from the copyright holder. To view a copy of this licence, visit http://creativecommons.org/licenses/by/4.0/.

\section{References}

1. Cheng J, Gao J, Shuai X, et al. The comprehensive summary of surgical versus non-surgical treatment for obesity: a systematic review and meta-analysis of randomized controlled trials. Oncotarget. 2016;7(26):39216-30. https://doi.org/10.18632/oncotarget.9581.

2. Schauer PR, Bhatt DL, Kirwan JP, et al. Bariatric surgery versus intensive medical therapy in obese patients with diabetes. NEJM. 2017;376:641-51. https://doi.org/10.1056/NEJMoa1600869.

3. Salminen P, Helmiö M, Ovaska J, et al. Effect of laparoscopic sleeve gastrectomy vs laparoscopic Roux-en-Y gastric bypass on weight loss at 5 years among patients with morbid obesity: the SLEEVEPASS randomized clinical trial. JAMA. 2018;319(3): 241-54. 
4. Peterli R, Wölnerhanssen BK, Peters T, et al. Effect of laparoscopic sleeve gastrectomy vs laparoscopic Roux-en-Y gastric bypass on weight loss in patients with morbid obesity: the SM-BOSS randomized clinical trial. JAMA. 2018;319(3):255-65. https://doi.org/10. 1001/jama.2017.20897.

5. Hofsø D, Fatima F, Borgeraas H, et al. Gastric bypass versus sleeve gastrectomy in patients with type 2 diabetes (Oseberg): a singlecenter, triple-blind, randomized controlled trial. Lancet Diabetes Endocrinol. 2019;7(12):912-24.

6. Avenell A, Robertson C, Skea Z, et al. Bariatric surgery, lifestyle interventions and orlistat for severe obesity: the REBALANCE mixed-methods systematic review and economic evaluation. Health Technol Assess. 2018;22(68):1-246. https://doi.org/10. 3310/hta22680.

7. Borgeraas H, Hofsø D, Hertel JK, et al. Comparison of the effect of Roux-en-Y gastric bypass and sleeve gastrectomy on remission of type 2 diabetes: a systematic review and meta-analysis of randomized controlled trials. Obes Rev. 2020;21(6):e13011. https://doi. org/10.1111/obr.13011.

8. Dixon JB, Zimmet P, Alberti KG, et al. Bariatric surgery: an IDF statement for obese Type 2 diabetes. Diabet Med. 2011;28(6):62842.

9. Stegenga H, Haines A, Jones K, et al. Identification, assessment, and management of overweight and obesity: summary of updated NICE guidance. BMJ. 2014;349:g6608.

10. Welbourn R, Hopkins J, Dixon JB, et al. Commissioning guidance for weight assessment and management in adults and children with severe complex obesity. Obes Rev. 2018;19:14-27.

11. Rubino F, Nathan DM, Eckel RH, et al. Metabolic surgery in the treatment algorithm for type 2 diabetes: a joint statement by International Diabetes Organizations. Diabetes Care. 2016;39(6): 861-77. https://doi.org/10.2337/dc16-0236.

12. Rubino F, Shukla A, Pomp A, et al. Bariatric, Metabolic, and diabetes surgery: what's in a name? Ann Surg. 2014;259:117-22. https://doi.org/10.1097/SLA.0b013e3182759656.

13. Buchwald H, Varco RL. Metabolic surgery (modern surgical monographs): Grune \& Stratton; 1978. ISBN 10: 0808910779 / ISBN 13: 9780808910770

14. Arterburn D, Wellman R, Emiliano A, et al. Comparative effectiveness and safety of bariatric procedures for weight loss: a PCORnet Cohort Study. Ann Intern Med. 2018;169(11):741-50. https://doi. org/10.7326/M17-2786.

15. Xia Q, Campbell JA, Ahmad H, et al. Bariatric surgery is a costsaving treatment for obesity-a comprehensive meta-analysis and updated systematic review of health economic evaluations of bariatric surgery. Obes Rev. 2020;21(1):e12932.

16. Welbourn R, le Roux CW, Owen-Smith A, et al. Why the NHS should do more bariatric surgery; how much should we do? BMJ. 2016;353:11472. https://doi.org/10.1136/bmj.i1472.

17. Welbourn R, Pournaras DJ, Dixon J, et al. Bariatric surgery worldwide: baseline demographic description and one-year outcomes from the Second IFSO Global Registry Report 2013-2015. Obes Surg. 2018;28:313-22.

18. Welbourn R, Hollyman M, Kinsman R, et al. Bariatric surgery worldwide: baseline demographic description and one-year outcomes from the Fourth IFSO Global Registry Report 2018. Obes Surg. 2019;29(3):782-95. https://doi.org/10.1007/s11695-0183593-1.

19. Buchwald H, Williams SE. Bariatric surgery worldwide 2003. Obes Surg 2004;14:1157-64

20. Buchwald H, Oien DM. Metabolic/bariatric surgery Worldwide 2008. Obes Surg. 2009;19:1605-11.

21. Buchwald H, Oien DM. Metabolic/bariatric surgery worldwide 2011. Obes Surg. 2013;23:427-36.
22. Angrisani L, Santonicola A, Iovino P, et al. Bariatric surgery worldwide 2013. Obes Surg. 2015;25:1822-32.

23. Angrisani L, Santonicola A, Iovino P, et al. IFSO worldwide survey 2016: primary, endoluminal, and revisional procedures. Obes Surg. 2018;28:3783-94.

24. Welbourn R, Gagner M, Naslund I, et al. First IFSO Global Registry Report 2014. Henley-on-Thames: Dendrite Clinical Systems Ltd; 2014. ISBN 978-0-9568154-9-1

25. Ramos A, Kow L, Brown W, Welbourn R, Dixon J, Kinsman R et al. Fifth IFSO Global Registry Report 2019. ISBN 978-19160207-3-3. https://www.ifso.com/pdf/5th-ifso-global-registryreport-september-2019.pdf

26. Non-Communicable Diseases Risk Factor Collaboration (NCDRisC). http://ncdrisc.org/data-downloads-diabetes.html. Accessed 30 March 2020

27. Centers for Disease Control and Prevention. National Diabetes Statistics Report 2020 Estimates of Diabetes and its Burden in the United States. https://www.cdc.gov/diabetes/pdfs/data/statistics/ national-diabetes-statistics-report.pdf Accessed 20 May 2020

28. International Diabetes Federation. IDF Diabetes Atlas, 9th edn. Brussels, Belgium: 2019. https://www.diabetesatlas.org. Accessed 20 May 2020

29. Martin M, Beekley A, Kjorstad R, et al. Socioeconomic disparities in eligibility and access to bariatric surgery: a national populationbased analysis. Surg Obes Relat Dis. 2010;6:8e15.

30. Kumar SB, Hamilton BC, Wood SG, et al. Is laparoscopic sleeve gastrectomy safer than laparoscopic gastric bypass? A comparison of 30-day complications using the MBSAQIP data registry. Surg Obes Relat Dis. 2018;14:264-9.

31. Chaar ME, Lundberg P, Stoltzfus J. Thirty-day outcomes of sleeve gastrectomy versus Roux-en-Y gastric bypass: first report based on Metabolic and Bariatric Surgery Accreditation and Quality Improvement Program database. Surg Obes Relat Dis. 2018;14(5):545-51. https://doi.org/10.1016/j.soard.2018.01.011.

32. Marso SP, Daniels GH, Brown-Frandsen K, et al. Liraglutide and cardiovascular outcomes in type 2 diabetes. NEJM. 2016;375:31122.

33. Pi-Sunyer X, Astrup A, Fujioka K, et al. A randomized, controlled trial of $3.0 \mathrm{mg}$ of liraglutide in weight management. NEJM. 2015;373:11-22.

34. Dixon JB. Regional differences in the coverage and uptake of bariatric-metabolic surgery: a focus on type 2 diabetes. Surg Obes Relat Dis. 2016;12(6):1171-7.

35. De Luca M, Tie T, Ooi G, et al. Mini gastric bypass-one anastomosis gastric bypass (MGB-OAGB)-IFSO Position Statement. Obes Surg. 2018;28(5):1188-206. https://doi.org/10.1007/s11695-0183182-3.

36. $\mathrm{Ng} \mathrm{M}$, Fleming $\mathrm{T}$, Robinson $\mathrm{M}$, et al. Global, regional, and national prevalence of overweight and obesity in children and adults during 1980-2013: a systematic analysis for the Global Burden of Disease Study 2013. Lancet. 2014;384:766-81.

37. Poelemeijer YQM, Liem RSL, Våge V, et al. Perioperative outcomes of primary bariatric surgery in North-Western Europe: a Pooled Multinational Registry Analysis. Obes Surg. 2018;28(12): 3916-22. https://doi.org/10.1007/s11695-018-3408-4.

38. Sakran N, Sherf-Dagan S, Blumenfeld O, et al. Incidence and risk factors for mortality following bariatric surgery: a Nationwide Registry Study [published correction appears in Obes Surg. 2018 Apr 25;]. Obes Surg. 2018;28(9):2661-9. https://doi.org/10.1007/ s11695-018-3212-1.

Publisher's Note Springer Nature remains neutral with regard to jurisdictional claims in published maps and institutional affiliations. 